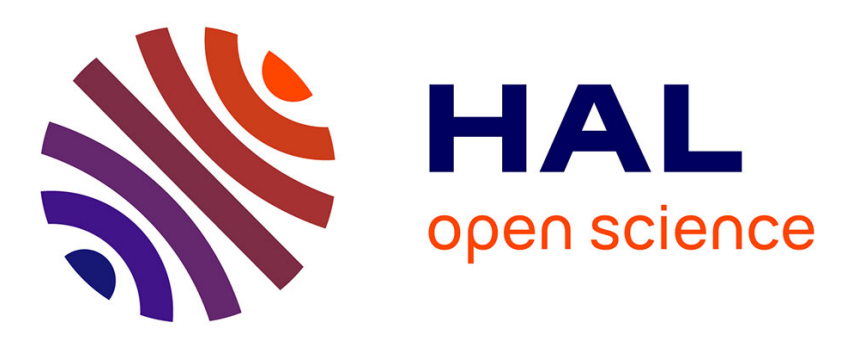

\title{
Assessment of hypothalamic-pituitary-adrenal axis and sympathetic nervous system activity in pregnant sows through the measurement of glucocorticoids and catecholamines in urine
}

\author{
M. Hay, F. Brulaud, M. Monnier, Pierre Mormède
}

\section{To cite this version:}

M. Hay, F. Brulaud, M. Monnier, Pierre Mormède. Assessment of hypothalamic-pituitary-adrenal axis and sympathetic nervous system activity in pregnant sows through the measurement of glucocorticoids and catecholamines in urine. Journal of Animal Science, 2000, 78, pp.420-428. hal-02693947

\section{HAL Id: hal-02693947 \\ https://hal.inrae.fr/hal-02693947}

Submitted on 1 Jun 2020

HAL is a multi-disciplinary open access archive for the deposit and dissemination of scientific research documents, whether they are published or not. The documents may come from teaching and research institutions in France or abroad, or from public or private research centers.
L'archive ouverte pluridisciplinaire HAL, est destinée au dépôt et à la diffusion de documents scientifiques de niveau recherche, publiés ou non, émanant des établissements d'enseignement et de recherche français ou étrangers, des laboratoires publics ou privés. 


\title{
Assessment of hypothalamic-pituitary-adrenal axis and sympathetic nervous system activity in pregnant sows through the measurement of glucocorticoids and catecholamines in urine ${ }^{1}$
}

\author{
M. Hay*, M.-C. Meunier-Salaün $\dagger$, F. Brulaud*, \\ M. Monnier $\$$, and P. Mormède ${ }^{*, 2}$ \\ *Neurogénétique et Stress, INSERM U471-INRA, Institut François Magendie, Bordeaux, F-33077, France; \\ $\dagger$ Station de Recherches Porcines, INRA, St Gilles, F-35590, France; and $\ddagger$ Laboratoire de Physiologie et de \\ Biomécanique de l'Exercice Musculaire, Université Rennes II, UFR APS, Rennes F-35044, France
}

\begin{abstract}
We validated the use of urine to monitor changes in the activity of both the hypothalamic-pituitary-adrenal (HPA) axis and the sympathetic nervous system (SNS) in swine. Ten pregnant sows were fitted with venous catheters $3 \mathrm{wk}$ after mating. In the early (wk 6), middle (wk 9), and late (wk 14) stages of gestation, blood and urine were collected over $24 \mathrm{~h}$ to monitor diurnal changes in plasma cortisol, urinary cortisol, and urinary catecholamines (norepinephrine [NE] and epinephrine [EPI]). Dexamethasone suppression tests (DST) and ovine corticotropin-releasing hormone $(\mathrm{CRH})$ challenge tests were also performed at each stage of gestation. All plasma and urinary values changed markedly around the clock. Diurnal variations of urinary cortisol were comparable to those in plasma, with a late nocturnal peak and a trough occurring in the evening. During the dark period, urinary catecholamines were lower than during the light period. Norepinephrine increased sharply after lights came on and
\end{abstract}

peaked after meal time. Epinephrine began to rise at the end of the dark period and peaked just before meal time. Average plasma cortisol increased with the stage of gestation, due to higher levels during daylight hours. Dexamethasone at $2000(20 \mu \mathrm{g} / \mathrm{kg}$ i.v. $)$ decreased plasma cortisol at 0830 and nocturnal cortisol excretion. The magnitude of the decrease in plasma ACTH and urinary cortisol after DST was lower in late than in early and midgestation, indicating increased feedback resistance at that stage. The $\mathrm{CRH}(1 \mu \mathrm{g} / \mathrm{kg}$ i.v. $)$ increased plasma and urinary cortisol. Peak levels occurred $30 \mathrm{~min}$ and 2 to $3 \mathrm{~h}$ after the injection, respectively. Catecholamines and cortisol in urine produced during the night (2000 to 0800) and the early morning (0400 to 0800 and 0800 to 0900 ) were highly correlated with their 24 -h excretion rate. These results indicate that it is possible to monitor changes in the HPA axis and SNS activity through urinary measurements in pigs.

Key Words: Hydrocortisone, Catecholamines, Urine, Pigs, Circadian Rhythm, Pregnancy

(C)2000 American Society of Animal Science. All rights reserved.

J. Anim. Sci. 2000. 78:420-428

\section{Introduction}

The hypothalamic-pituitary-adrenal (HPA) axis and the sympathetic nervous system (SNS) are markedly activated during stress, leading to the release of glucocorticoids and catecholamines, respectively. The mea-

\footnotetext{
${ }^{1}$ This study was supported by a special grant from INRA (AIP "Neurobiologie de l'adaptation et bien-être animal"). We are grateful to J. C. Hulin, Y. Lebreton, M. Massard, A. M. Mounier, A. Pinczon du Sel, and G. Reuzau for their technical assistance in the catheterization of the sows, the diligent care of the animals, and plasma hormone assays. M. Hay is the recipient of a fellowship from the National Veterinary School of Toulouse.

${ }^{2}$ To whom correspondence should be addressed: (phone: 33-557573753; fax: 33-557-573752; E-mail: mormede@bordeaux.inra.fr).

Received April 19, 1999.

Accepted August 10, 1999.
}

surement of circulating levels of these hormones has provided information on the effects of acute environmental and psychological challenges in farm animals (Dantzer and Mormède, 1983). However, little is known about how long-lasting conditions affect neuroendocrine activity. Indeed, chronic activation of the SNS and HPA axis is usually associated with only a slight to moderate increase in catecholamines and glucocorticoids. Because of the pulsatility and the circadian variations in the secretion of these hormones, samples must be collected very frequently to obtain reliable basal values. Moreover, the blood sampling procedure may itself elicit acute stress responses, thus interfering with the effect of the factors under study.

Alternatives to plasma sampling include urine collection, which offers advantages for studying of HPA and SNS activity: 1) urine is the main elimination route 
for catecholamines and glucocorticoids; 2) urine can be collected noninvasively when spontaneously voided; and 3) excretion products in urine accumulate over several hours. Thus, concentrations in urine can be considered as more integrative than those in plasma, and they may be more accurate for the detection of variations in HPA axis and SNS basal activity.

Our objective for this study was to validate the use of urine to monitor changes in the activity of the HPA axis and SNS in sows. We examined whether urinary catecholamines and glucocorticoids vary in parallel with their secretion (diurnal changes, response to dexamethasone and corticotropin-releasing hormone). The relevance of the information provided by a single, early morning urine collection for the assessment of the basal excretion rate of these hormones was also investigated.

\section{Materials and Methods}

\section{Animals and Housing}

Pregnant, multiparous sows ( $\mathrm{n}=10 ; 180$ to $260 \mathrm{~kg}$ body weight; Large White $\times$ Landrace) were used in this experiment. Three weeks after mating, the sows were transferred to the experimental room where they remained throughout the gestation period. Animals were housed in individual stalls $(.6 \times 2.0 \mathrm{~m})$ on concrete floors covered with wood shavings, except for a $.4-\mathrm{m}$ slatted dunging area in the rear of the stalls. Lights were on between 0800 and 2000, and the ambient temperature remained within 20 to $25^{\circ} \mathrm{C}$.

Feed was delivered once a day at 0900 . All sows were initially fed a standard mixed diet based on cereals and soybeans $(2.6 \mathrm{~kg} / \mathrm{d})$ until d 40 of gestation. Thereafter, sows were fed with fibrous diets because this study was part of a wider experiment to test the influence of dietary fibers on the behavior and metabolism of pregnant sows. Throughout the remainder of gestation, half of the sows received either a high-fiber $\operatorname{diet}(36.16 \%$ $\mathrm{NDF}, 3.0 \mathrm{~kg} / \mathrm{d})$ or a low-fiber diet $(18.89 \% \mathrm{NDF}, 2.4 \mathrm{~kg} /$ d), balanced for energy (33.4 MJ/d) (Ramonet et al., 1999). Water was available for ad libitum consumption through nipple drinkers.

To collect serial blood samples, each sow was fitted with a permanent jugular vein catheter under sterile conditions and general anesthesia, as previously described (Camous et al., 1985). Surgery was performed at the entrance of the sows into the experimental room (3 wk after mating). The cannulas were maintained by regular and postsampling flushing with sterile heparinized physiological saline. The sows were weighed at the start of the experiment and again at middle and late gestation.

\section{Design}

Urine and blood were collected on two successive days at three stages of gestation: early (wk 6), middle (wk 9 ), and late (wk 14) gestation. In the early afternoon before each sampling period, the sows were fitted with an inflatable vesical catheter (Bard Folex catheter, size 18, $30 \mathrm{~mL}$, Bard SA, Trappes, France) that allowed continuous urine collection into containers located at the back of the stalls, as previously described (Pollmann et al., 1979).

For the circadian study (d 1), urine and blood samples were collected at 0000, 0400, 0800, 0900, 1200, 1600, and 2000. Additional blood samplings were conducted around meal time (0830, 0915, and 0930). Immediately after the last sampling at 2000, the sows were intravenously injected with dexamethasone $(20 \mu \mathrm{g} / \mathrm{kg}$, Soludecadron, MSD, Riom, France) to suppress endogenous corticosteroid production (dexamethasone suppression test [DST]). On d 2, urine was collected at 0800 and 0900. Blood was sampled at 0830 and 0900. At 0900, five sows received $1 \mu \mathrm{g} / \mathrm{kg}$ of synthetic ovine corticotropin-releasing hormone (oCRH, Neosystem, Strasbourg, France) through the i.v. catheter. Blood and urine from those sows were subsequently collected at 0930, 1000, and then hourly until 1600 . Additional blood sampling was conducted at 0915.

Sampling Procedure

Before each blood sample was collected, approximately $5 \mathrm{~mL}$ of blood was drawn and discarded to remove possible residual blood or physiological saline from the catheter. For corticosteroid determination, blood samples were immediately transferred to ice-cold, heparinized tubes and then centrifuged for $10 \mathrm{~min}$ at $4^{\circ} \mathrm{C}$. Plasma was stored at $-80^{\circ} \mathrm{C}$ until hormone analysis was completed. For ACTH assessment, $1 \mathrm{~mL}$ of blood was transferred into ice-cold tubes containing $100 \mu \mathrm{L}$ of Antagosan (aprotinine, Hoechst, Puteaux, France) and $10 \mu \mathrm{L}$ of EDTA. Immediately after centrifugation $\left(10 \mathrm{~min}, 4^{\circ} \mathrm{C}\right.$ ), plasma was collected and stored at $-80^{\circ} \mathrm{C}$ until completion of the analysis. At each urine sampling, the volume in the containers was recorded. Samples of urine were kept and acidified with $6 \mathrm{M} \mathrm{HCl} \mathrm{(1 \%}$ of urine volume) and were immediately frozen at $-80^{\circ} \mathrm{C}$ in $30-\mathrm{mL}$ aliquots.

\section{Hormone Analyses}

Plasma concentrations of cortisol were quantified with an immunoassay, as previously described (Meunier-Salaün et al., 1991). The intra- and interassay CV were 7.6 and $12.5 \%$, respectively.

Adrenocorticotropin levels were determined in plasma collected at 0830, 0915, 0930, 1000, and 1100 on $\mathrm{d} 1$, and in all plasma samples collected following $\mathrm{CRH}$ challenge using commercial two-site immunoradiometric assay test kits (IRMA-ACTH, Nichols Institute Diagnostics, San Juan Capistrano, CA). This assay protocol has been validated for pig plasma (Mormède et al., 1994). The intra- and interassay CV were 3.0 and $7.8 \%$, respectively.

Urinary free catecholamines (norepinephrine [NE] and epinephrine $[\mathbf{E P I}]$ ) were assayed using an ion-ex- 
change purification procedure followed by liquid chromatography with electrochemical detection, as previously described (Hay and Mormède, 1997a). Briefly, urine samples were loaded on cationic columns and the catecholamines were eluted with boric acid. The eluates were then assayed using HPLC with electrochemical detection with an oxidizing potential of $+.65 \mathrm{~V}$. The intra- and interassay CV were 7.0 and $7.1 \%$ for NE and 6.5 and $11.6 \%$ for EPI, respectively.

Urinary cortisol and cortisone (the oxidized metabolite of cortisol) were assayed using a solid-phase extraction procedure followed by HPLC with UV absorbance detection $(254 \mathrm{~nm})$, as previously described (Hay and Mormède, 1997b). Briefly, the filtered urine samples were loaded onto $\mathrm{C} 18$ cartridges mounted on a vacuum processing station. Corticosteroids were eluted using absolute ethanol. After evaporation of ethanol, the dried residues containing corticosteroids were redissolved in mobile phase and injected into the HPLC system. The intra- and interassay were 7.4 and $10.6 \%$ for cortisol and 5.4 and $10.9 \%$ for cortisone, respectively.

Creatinine levels were determined using a colorimetric quantitative reaction (Procedure 500, Sigma Diagnostics, Saint-Quentin-Fallavier, France). This method is based on the bleaching of the color derived from the reaction between creatinine and alkaline picrate (Jaffe's reaction) when the mixture is acidified. Thus, the difference in color intensity measured at $500 \mathrm{~nm}$ before and after acidification of the mixture is proportional to creatinine concentration.

\section{Data Analyses}

The STATISTICA package (Statsoft, Tulsa, OK) was used for the analyses, except for regression analyses. Concentrations of all hormones were analyzed after log transformation to fit the Shapiro-Wilk test of normality. Data were submitted to an analysis of variance with stage of gestation and time of day as within-subject factors and diet as a between-subject factor. When significant, analysis of variance was followed by the Newman Keuls multiple comparison test. Regression analyses were performed using the PRISM package (GraphPad Software Inc., San Diego, CA).

\section{Results}

One sow aborted during the experiment, and two bladder catheters were blocked during the first period (early gestation). Therefore, diurnal changes of hormone levels and the effect of dexamethasone were analyzed on the data obtained from nine animals, and the effect of CRH on urinary hormone levels was analyzed on the data obtained from four sows. The dietary treatment had no effect on any of the variables under study.

\section{Reliability of the Creatinine to Correct for the Variable Dilution of Urine}

In order to confirm the reliability of creatinine to correct for the variable dilution of urine related to water
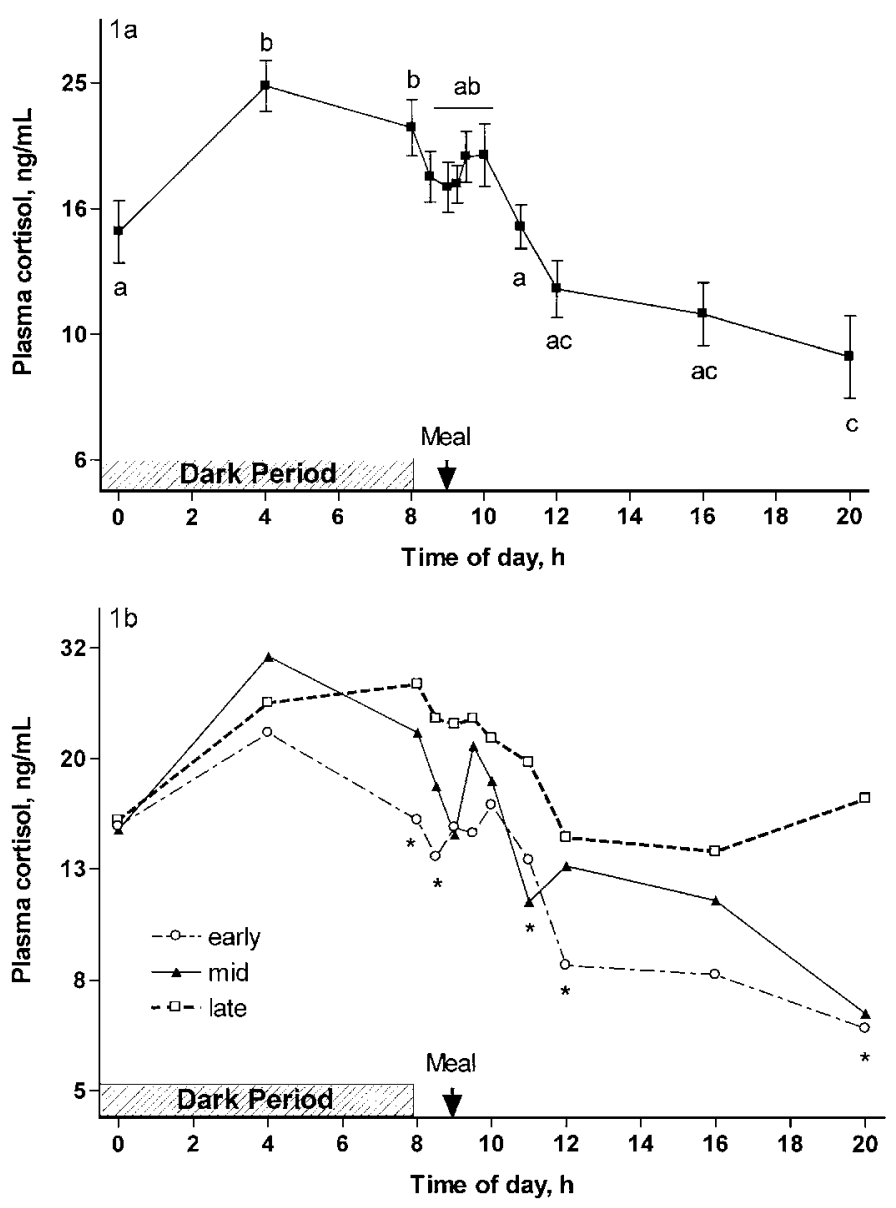

Figure 1. (a) Diurnal changes in mean ( \pm SEM) plasma cortisol. Lack of a common letter between two sampling times indicates different concentrations $(P<.05)$. (b) Diurnal changes in mean $( \pm$ SEM) plasma cortisol for each stage of gestation considered separately. The asterisks indicate the times when there was a significant effect for the stage of gestation as indicated by analysis of variance.

intake, the concentrations of the hormones expressed as a function of creatinine concentration were plotted against their excretion rate. Regression analysis revealed significant correlations for cortisol $\left(\mathrm{r}_{361}=.90, P\right.$ $<.0001)$, cortisone $\left(\mathrm{r}_{361}=.92, P<.0001\right)$, NE $\left(\mathrm{r}_{361}=\right.$ $.75, P<.0001)$, and EPI $\left(\mathrm{r}_{361}=.82, P<.0001\right)$. Hence, hormone levels in urine will be presented as concentrations relative to creatinine in the remainder of this article.

\section{Circadian Variations}

The excretion of creatinine was not influenced by the stage of gestation and remained stable throughout the 24-h period, averaging $320( \pm 33) \mathrm{mg} / \mathrm{h}$.

Plasma cortisol changed markedly during the 24-h period $(P<.0001$, Figure 1a). A normal periodicity was observed, with high levels in the early morning and a nadir at 2000, just before the onset of darkness. After meal time there was a slight, nonsignificant increase 


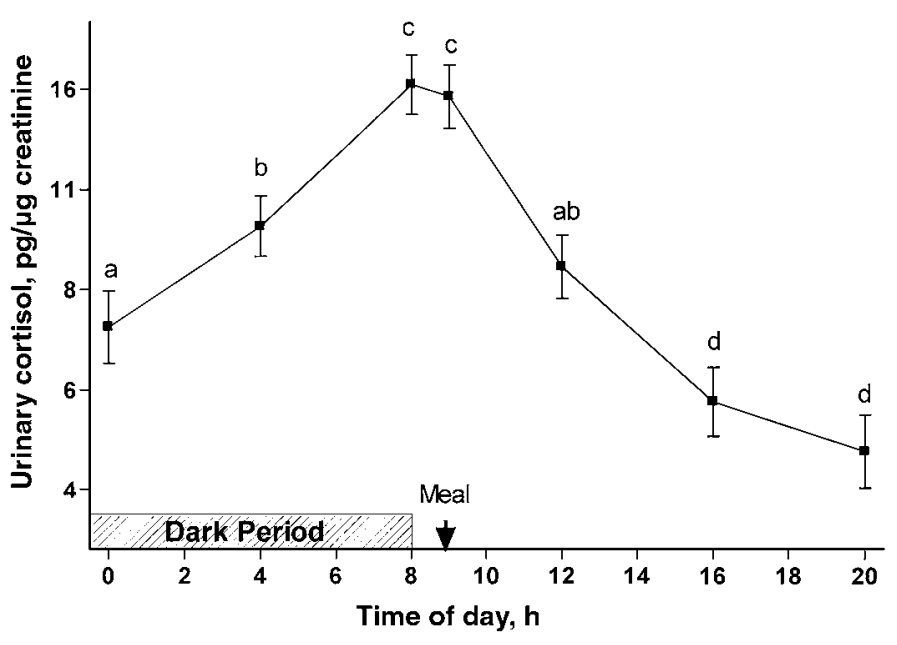

Figure 2. Diurnal changes in mean $( \pm$ SEM) urinary cortisol. Lack of a common letter between two sampling times indicates different concentrations $(P<.05)$.

in plasma cortisol. There was a 2.7 -fold increase (9.2 vs $24.8 \mathrm{ng} / \mathrm{mL}, P<.0001$ ) from minimal to maximum cortisol concentrations. Mean plasma cortisol levels increased with the stage of gestation $(P<.001)$. In late gestation, they were $19.95 \mathrm{ng} / \mathrm{mL}$, compared to 12.6 and $15.5 \mathrm{ng} / \mathrm{mL}$ in early and middle gestation $(P<.001$ and $<.05$, respectively). The difference between middle and early gestation was also significant $(P<.05)$. Noticeably, the differences among the stages of gestation were apparent during daylight hours only, resulting in less prominent diurnal changes in late compared to early and middle gestation (Figure $1 \mathrm{~b}$ ).

The concentrations of both urinary cortisol and cortisone fluctuated widely throughout the 24 -h period ( $P$ $<.0001)$. The pattern of the diurnal changes in urinary cortisol was parallel to that seen in plasma (Figure 2). Urinary cortisol peaked in the early morning and declined steadily during daylight hours, reaching a nadir in the evening. There was almost a fourfold increase in urinary cortisol levels $(4.5 \mathrm{vs} 16.0 \mathrm{pg} / \mu \mathrm{g}$ creatinine, $P$ $<.0001$ ) from minimum to maximum. Although average urinary cortisol increased with stage of gestation as in plasma $(10.3,11.4$, and $15.3 \mathrm{pg} / \mu \mathrm{g}$ creatinine in early, middle, and late gestation, respectively), the differences among stages failed to reach significance. Cortisone changed in parallel with cortisol (data not shown). There was a 2.3-fold increase from minimum to maximum cortisone concentrations ( $5.7 \mathrm{vs} 13.5 \mathrm{pg} / \mu \mathrm{g}$ creatinine, $P<.0001$ ). Noticeably, there was a significant effect of time for the ratio between cortisol and cortisone $(P<.0001)$. The cortisol:cortisone ratio was maximal in the early morning (1.14 and 1.16 in the urine collected over the 0400 to 0800 and 0800 to 0900 intervals, respectively). It decreased thereafter, reaching a nadir in the evening (.76 in the urine collected over the 1600 to 2000 interval). The cortisol:cortisone ratio was lower in late than in early gestation (.84 vs $1.22, P<.05)$ and was intermediate in midgestation (1.00).
The concentration of both NE and EPI in urine also displayed marked diurnal changes $(P<.0001)$. Average $\mathrm{NE}$ levels were low during the dark period (Figure 3a), increasing sharply after light onset and peaking within the 0900 to 1200 interval. The amplitude of the variation from minimum to maximum approached twofold (3.9 vs $6.4 \mathrm{pg} / \mu \mathrm{g}$ creatinine, $P<.0001$ ). The EPI concentrations remained low during most of the dark period (Figure $3 \mathrm{~b}$ ) and then started to increase within the 0400 to 0800 interval, reaching a maximum during the hour before meal time. At that time, the concentrations were fivefold higher compared to the trough (4.9 vs $1.0 \mathrm{pg} /$ $\mu$ g creatinine, $P<.0001)$. Thereafter, there was a progressive decline in EPI levels until 2000. There were no changes in NE and EPI with the stage of gestation.

\section{Dexamethasone Suppression Test}

Dexamethasone decreased plasma ACTH at 0830 compared to the values measured on the previous day
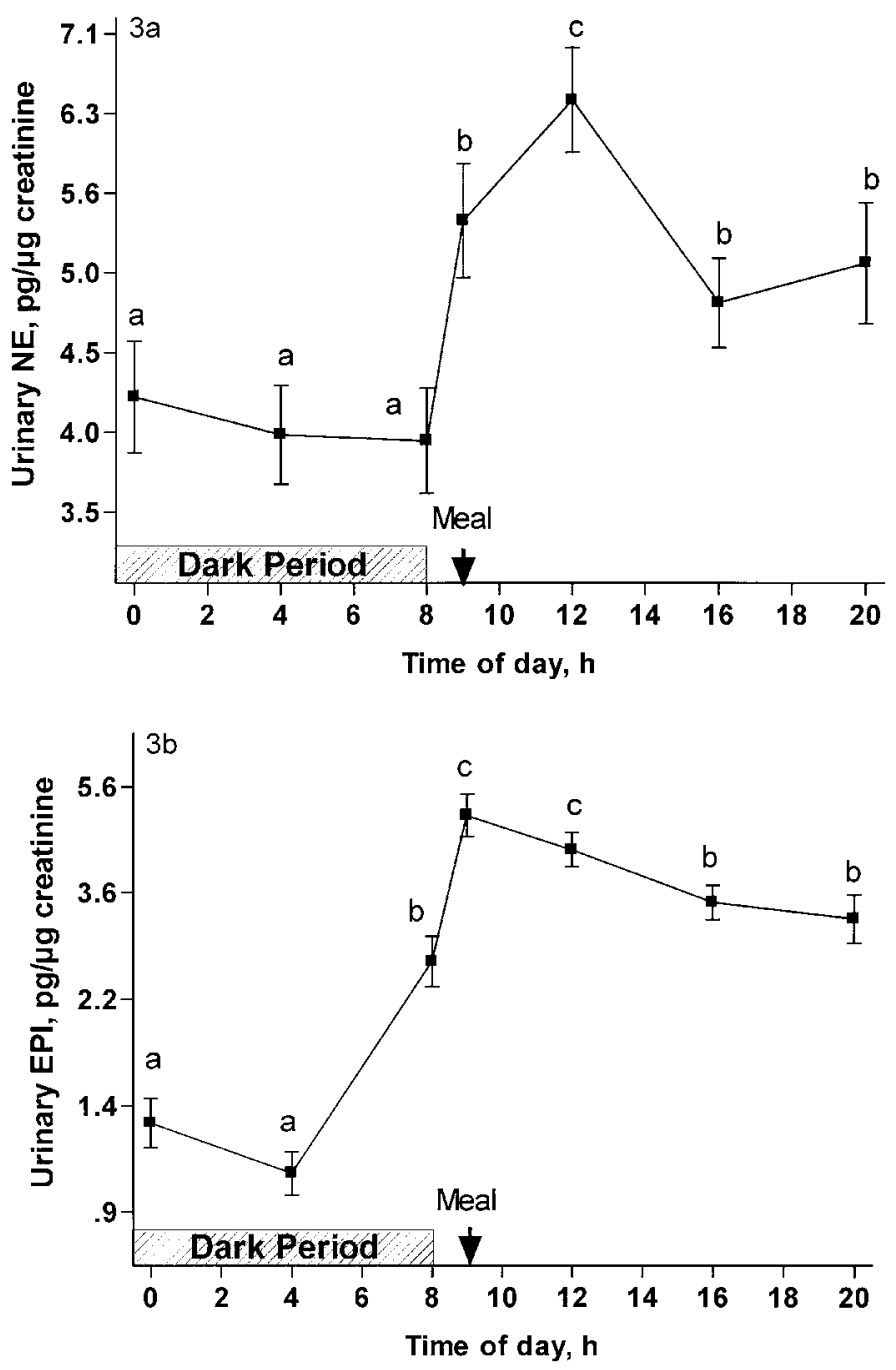

Figure 3. Diurnal changes in mean ( \pm SEM) urinary (a) norepinephrine [NE]; and (b) epinephrine [EPI]. Lack of a common letter between two sampling times indicates different concentrations $(P<.05)$. 
(.2 vs $4.4 \mathrm{ng} / \mathrm{mL}, P<.0001$ ). Basal ACTH did not differ among the stages of gestation. However, the magnitude of the drop after DST was lower in late than in early and middle gestation (Figure 4a), resulting in a significant stage of gestation $\times$ dexamethasone treatment interaction $(P<.01)$. Dexamethasone also decreased plasma cortisol at 0830 (4.4 vs $23.6 \mathrm{ng} / \mathrm{mL}, P<.0001)$. Basal cortisol was higher in late gestation (Figure $4 \mathrm{~b}$ ), but there was no difference in the magnitude of the decrease after DST between the stages of gestation. In the 2000 to 0800 urine, dexamethasone led to a decrease in cortisol and cortisone similar to that observed in plasma (2.6 vs $13.0 \mathrm{pg} / \mu \mathrm{g}$ creatinine and $3.9 \mathrm{vs} 13.1 \mathrm{pg} / \mu \mathrm{g}$ creatinine for cortisol and cortisone, respectively, $P<.0001$ ). Although basal nocturnal cortisol excretion was not different among the stages of gestation, the magnitude of the drop after DST was lower in late than in early and middle gestation (Figure 4c), resulting in a significant interaction between stage of gestation and treatment $(P<.05)$.

\section{Corticotropin-Releasing Hormone Challenge}

Corticotropin-releasing hormone (CRH) elicited a 20fold increase in plasma ACTH within 15 min (45.7 vs $2.0 \mathrm{pg} / \mathrm{mL}, P<.0001$, Figure 5a). Concentrations of ACTH decreased until the end of the period but remained above the levels measured on the previous day between 0830 and $1100(P<.001)$. The $\mathrm{CRH}$ also induced a 10 -fold increase in plasma cortisol within 30 $\min (50.2$ vs $4.4 \mathrm{ng} / \mathrm{mL}, P<.0001$ ) (Figure $5 \mathrm{~b}$ ). Like ACTH, cortisol levels subsequently decreased but were still above control levels at the end of the collection period ( $20.8 \mathrm{vs} 11.3 \mathrm{ng} / \mathrm{mL}$ at $1600, P<.0003$ ). In urine, there was a sharp rise in cortisol within the 0930 to 1000 interval (Figure 5c). Peak urinary cortisol was measured 2 to $3 \mathrm{~h}$ after $\mathrm{CRH}$ injection (30.0 and 30.1 $\mathrm{pg} / \mu \mathrm{g}$ creatinine, compared to the $1.7 \mathrm{pg} / \mu \mathrm{g}$ creatinine preinjection levels, $P<.0001$ ). There was thereafter a progressive, but nonsignificant, decrease until the end of the collection period. Cortisone changed in parallel to cortisol, reaching a peak $3 \mathrm{~h}$ after $\mathrm{CRH}$ injection (31.7 $\mathrm{pg} / \mu \mathrm{g}$ creatinine). Post-CRH levels of ACTH, plasma cortisol, and urinary cortisol were not different between the stages of gestation.

\section{Morning vs 24-Hour Measurements}

The data collected during the circadian cycle study were used to assess the relationship between catecholamine and glucocorticoid concentrations in the urine produced during the night (2000 to 0800) and the average basal excretion of these hormones (amount per $24 \mathrm{~h}$ ). Cortisol and cortisone concentrations in night urine were highly correlated with the 24-h excretion of these hormones $\left(\mathrm{r}_{27}=.83\right.$ and .92 , respectively, $\left.P<.0001\right)$. Catecholamines in night urine were also correlated with their 24 -h excretion rate $\left(\mathrm{r}_{27}=.84\right.$ and .71 for $\mathrm{NE}$ and EPI, respectively, $P<.0001)$. Similar analyses were
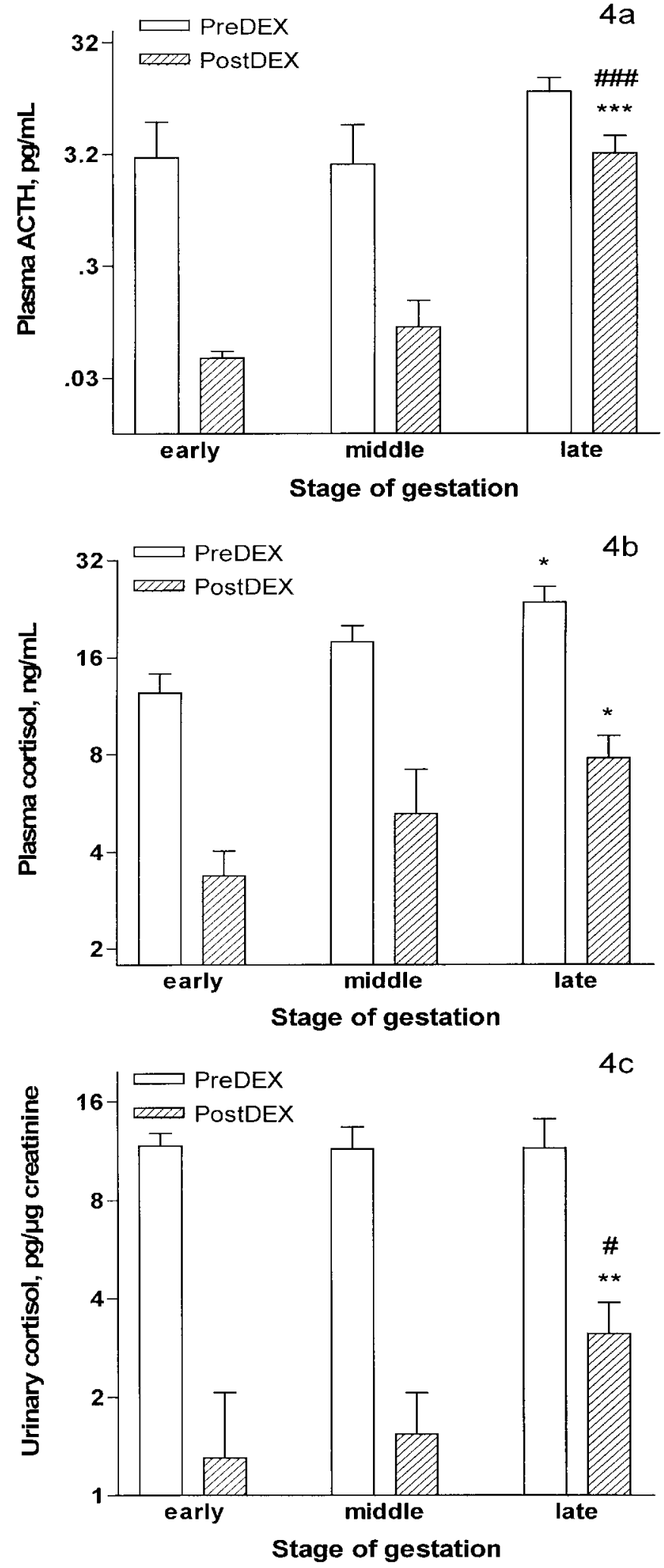

Figure 4. Effect of dexamethasone $(20 \mu \mathrm{g} / \mathrm{kg} \mathrm{BW})$ on mean ( \pm SEM) (a) plasma ACTH at 0830, (b) cortisol at 0830, and (c) nocturnal (2000 to 0800) urinary cortisol for each stage of gestation considered separately. The asterisks indicate a significant difference between late and early gestation stages $\left({ }^{*} P<.05,{ }^{* *} P<.01,{ }^{* * *} P<.001\right)$. The symbols indicate a significant difference between late and midgestation stages $\left({ }^{\#} P<.05,{ }^{\# \#} P<.001\right)$. 

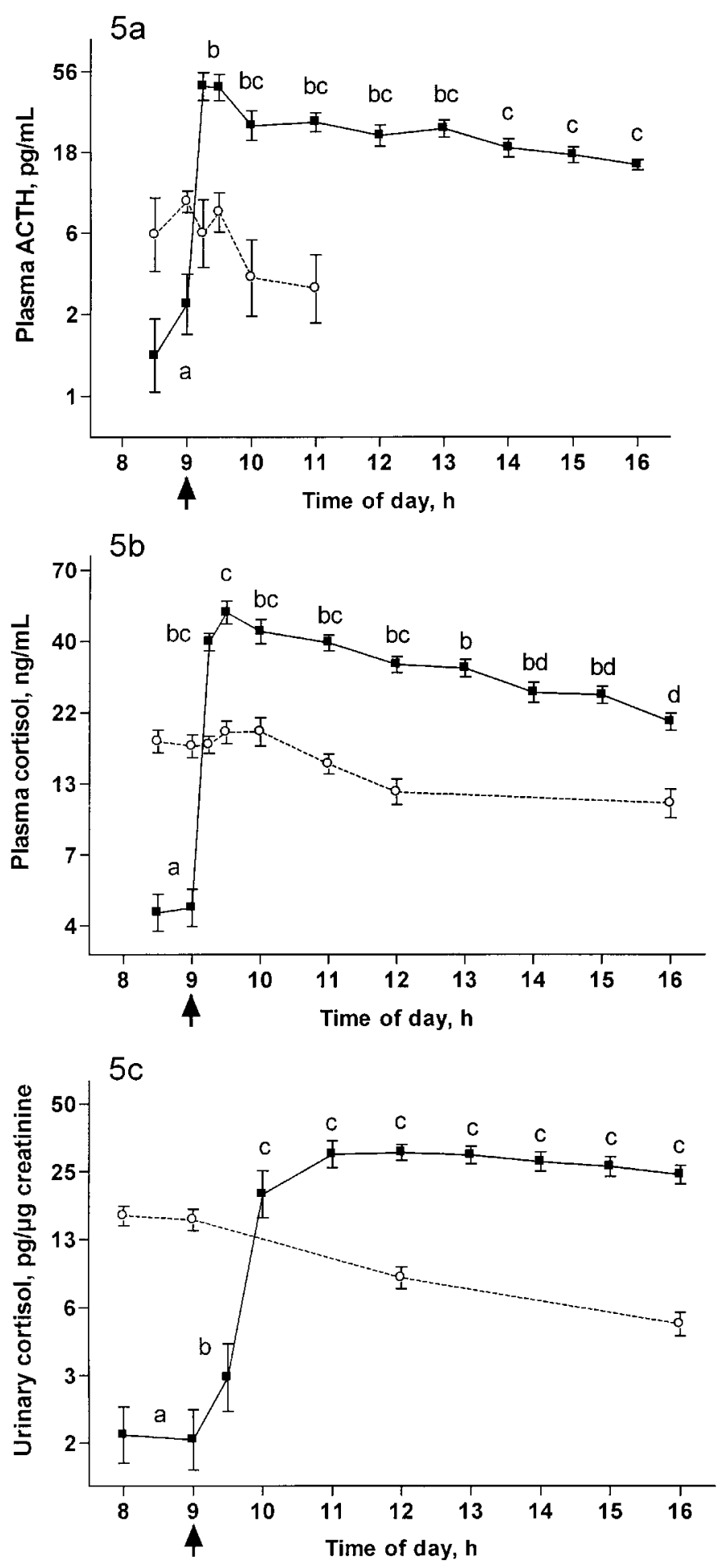

Figure 5. Effect of ovine corticotropin-releasing hormone (oCRH; $1 \mu \mathrm{g} / \mathrm{kg} \mathrm{BW}$ ) on mean ( \pm SEM) (a) plasma $\mathrm{ACTH}$, (b) plasma cortisol, and (c) urinary cortisol. The injection was performed at 0900 (arrow). Lack of a common letter between two sampling times after oCRH indicates different concentrations $(P<.05)$. For comparison, the average concentrations obtained on previous day have been added for each parameter (dotted lines). performed with the concentrations obtained from urine collected over the 0400 to 0800 and 0800 to 0900 intervals. The correlation with the 24 -h excretion rate was significant for all hormones $\left(\mathrm{r}_{27}=.65\right.$ to $\left..93, P<.0001\right)$.

\section{Discussion}

The primary purpose of this study was to investigate the feasibility of urinary glucocorticoid and catecholamine measurement for monitoring the activity of both the HPA axis and SNS in pigs. Our results show that 1) moderate changes in catecholamine and glucocorticoid secretion, as seen during the diurnal cycle, can be easily detected in urine, 2) functional tests of the pituitaryadrenal function can be monitored through urinary measurements of glucocorticoids, and 3) hormone levels in early morning urine reflect the average 24 -h excretion of catecholamines and glucocorticoids. Additionally, the HPA axis activity was shown to increase with the stage of gestation.

\section{Diurnal Changes}

The pattern of the diurnal changes in plasma cortisol observed in this study, with increased levels at the end of the night and a trough around the onset of darkness, is in accordance with that observed by others in pigs (Barnett et al., 1981; Janssens et al., 1995b). The results of this study show that glucocorticoid in swine urine evince changes similar to those in plasma. A parallel between diurnal changes of plasma and urinary cortisol in humans has been also reported (Fibiger et al., 1984; Morineau et al., 1997). In accordance with those reports, we found a lag time between plasma and urinary peaks of cortisol, which likely reflects the additional time required for cortisol to be cleared from the circulation. Because of the large sampling interval we used, the lag time between plasma and urinary changes cannot be exactly inferred. However, close examination of the slopes between the successive points of the circadian profiles suggests that it may be approximately $2 \mathrm{~h}$. Noticeably, the cortisol:cortisone ratio did not remain constant during the 24-h period, as reported for humans (Morineau et al., 1997). In this study, it was maximal in the early morning and reached a nadir in the evening, which may reflect changes in the activity of the $11 \beta$ hydroxysteroid dehydrogenase isoform 2 (11 $\beta$-HSD2), the enzyme that catalyzes the dehydrogenation of the active cortisol into the inactive cortisone in kidney (Stewart and Edwards, 1990).

Probably due to the difficulties in obtaining reliable basal estimates of plasma catecholamines, there have been few attempts to investigate diurnal changes in their secretion in pigs, except for the study of Klemcke et al. (1989). Using a 6-h interval sampling design, these authors did not detect any diurnal changes in plasma NE and EPI concentrations. However, a clear circadian rhythm of catecholamine secretion has been demonstrated in other species, with shorter plasma 
sampling intervals or urinary analysis (Mullen et al., 1981; Linsell et al., 1985; Del Rio et al., 1990). The results obtained in the present experiment, with the lowest levels occurring at night, is in complete accordance with the pattern of diurnal changes reported in the aforementioned studies. It has been suggested that differences in body posture and physical activity account for most of the diurnal changes in catecholamine secretion (Scöfl et al., 1997). Accordingly, the sows in the present experiment woke up promptly when the lights were switched on and showed agitation until feeding time. After eating, most of them remained active for a while, displaying high amounts of stereotypic behaviors. A similar influence of meal distribution on the pattern of diurnal activity has been reported by others (Cariolet and Dantzer, 1984). This period of high activity is likely to be responsible for the increase in catecholamine excretion observed in the morning. However, EPI levels were already elevated in the urine collected over the 0400 to 0800 interval, when the sows were still sleeping. This late nocturnal increase of EPI may be related to a reduced energy disposal at that time because the sows involved in this study were feed-restricted and usually ate their 24 -h ration within a few minutes. Increased EPI secretion has been reported in humans between 12 and $26 \mathrm{~h}$ of fasting, whereas NE levels decreased slightly in the meanwhile (Cryer, 1980). According to Young et al. (1984), the stimulation of EPI secretion during fasting may favor the maintenance of energy substrate disposal, whereas the release of NE is suppressed to spare energy.

\section{Stage of Gestation}

Limited data are available about the variation of cortisol secretion throughout gestation in pigs (Kattesh et al., 1997; Klemcke, 1997; Klemcke and Christenson, 1997). In those studies, no change in plasma cortisol was found, at least until d 105 of gestation. In the present experiment, however, daily average plasma cortisol increased with the stage of gestation. This compares favorably with the results obtained with humans, in whom total plasma cortisol rises progressively as pregnancy advances (Smith and Thomson, 1991). It has been suggested that this elevation is due in part to the estrogen-induced elevation of cortisol-binding globulin (Rosner, 1990). This may explain why we did not detect significant changes in urinary cortisol levels with the stage of gestation. This hypothesis is supported by two lines of evidence. First, urinary cortisol displays a close linear correlation with the unbound plasma cortisol, the sole fraction available for glomerular filtration (Lindholm, 1973). Second, it has been shown that the concentration of free cortisol increases more slowly and in an attenuated form throughout pregnancy, as compared to that of total cortisol (Brien and Dalrymple, 1976; Meulenberg and Hofman, 1990). Further studies are required to ascertain whether the unbound plasma cortisol changes in parallel with urinary cortisol during pregnancy in pigs.

\section{Functional Tests}

The dexamethasone suppression test is classically used to assess pituitary-adrenal disturbances induced by chronic stress. It is used in psychiatric medicine to investigate neuroendocrine alterations associated with various disorders, such as depression (Gold et al., 1996). Resistance to dexamethasone suppression is one of the features generally associated with increased pituitaryadrenal function, as seen during chronic stress. In pigs, for instance, severe area restriction enhanced resistance to dexamethasone, possibly in relation to the aversiveness of this condition (Meunier-Salaün et al., 1987). In the present experiment, the decrease in plasma and urinary cortisol following DST were comparable, which suggests that urine may be used instead of plasma to monitor the response to DST. Indeed, the accuracy of urinary cortisol measurements for the assessment of various degrees of HPA axis suppression has already been emphasized in depressed and normal human subjects (Maes et al., 1991; Tomitaka et al., 1996). Furthermore, the difference in the efficacy of dexamethasone to lower cortisol levels between the gestation stages was evident only in urine. Hence, the magnitude of the drop in urinary cortisol levels following DST was reduced in late compared to early and midgestation, which is indicative of an increased feedback resistance at that stage. This result is congruent with the reduced suppression of plasma ACTH and with the rise of average plasma cortisol levels observed in late gestation. Accordingly, nocturnal urine may provide more accurate information on the degree of HPA axis resistance than a single plasma sample.

Another feature generally associated with increased function of the HPA axis is an enhanced adrenocortical reactivity, which can be assessed with an ACTH or CRH challenge test. Meunier-Salaün et al. (1987) found that pigs maintained at high stocking density display enhanced cortisol response to ACTH. More recently, Janssens et al. (1995a) injected CRH to tethered and loose female pigs and found increased sensitivity of the adrenal cortex in the former compared to the latter. Conversely, the sensitivity of the pituitary to $\mathrm{CRH}$ remained unaltered. The response of plasma ACTH and cortisol following $\mathrm{CRH}$ administration that we report is similar to that observed by others for female pigs (Janssens et al., 1995a). In the latter study, low and high doses of $\mathrm{CRH}$ induced comparable cortisol peak values, whereas ACTH peak levels increased continuously. However, there was a dose-dependent increase of the duration of the release of cortisol. With doses of $\mathrm{CRH}$ of .52 and $1.26 \mu \mathrm{g} / \mathrm{kg}$, these authors noted that plasma ACTH and cortisol were still elevated at the end of the 3-h sampling period. The present study shows that they remain above basal values at least $7 \mathrm{~h}$ following $1 \mu \mathrm{g} / \mathrm{kg}$ of $\mathrm{CRH}$. In accordance with the lag time 
necessary for cortisol to be cleared from the circulation, urinary cortisol peaked 90 min later than in plasma, that is, $2 \mathrm{~h}$ after $\mathrm{CRH}$ injection. This figure compares favorably with that reported by Carlstead et al. (1992), who found a peak in cortisol excretion $2 \mathrm{~h}$ after an injection of ACTH in cats. Except for this lag time, the increase of urinary cortisol was similar to that observed in plasma. As with DST, this result shows that sampling urine may offer a noninvasive alternative to plasma sampling to monitor the response to ACTH or $\mathrm{CRH}$ challenge.

Potential Validity of a Single, Morning Sampling of Urine

There was a high correlation between the excretion rate of catecholamines and glucocorticoids over $24 \mathrm{~h}$ and their concentrations in urine produced during the night or the early morning. Indeed, the examination of individual circadian profiles revealed that variations between sows in hormone concentrations were most prominent in nocturnal (2000 to 0800) and early morning (0800 to 0900) urine. Because sows usually urinate shortly after they stand up at the time the lights are switched on, urine collected at that time may be used to assess the mean basal activity of HPA axis and SNS.

\section{Implications}

Investigating adaptive responses to husbandry practices is often difficult in pigs. This is due to a limited access to blood and to the functional characteristics of neuroendocrine systems, such as pulsatility and sensitivity to handling. Measuring corticosteroids and catecholamines in urine is a noninvasive method for the assessment of small variations in the activity of the hypothalamic-pituitary-adrenal (HPA) axis and the sympathetic nervous system (SNS). Urinary measurements may also be used in combination with challenge tests for the study of the adrenocortical function, and possibly for the study of stress responses induced by specific, acute management procedures. Assessing the basal status of the HPA axis and the SNS from a single, morning urine collection offers promising perspectives for the evaluation of neuroendocrine activity associated with a wide range of husbandry and experimental conditions.

\section{Literature Cited}

Barnett, J. L., J. C. Wingfield, G. M. Cronin, and A. W. Makin. 1981. Effect of photoperiod and feeding on plasma corticosteroid concentrations and maximum corticosteroid-binding capacity in pigs. Aust. J. Biol. Sci. 34:577-585.

Brien, T. G., and I. J. Dalrymple. 1976. Longitudinal study of the free cortisol index in pregnancy. Br. J. Obstet. Gynaecol. 83:361-367.

Camous, S., A. Prunier, and J. Pelletier. 1985. Plasma prolactin, LH, FSH and estrogen excretion patterns in gilts during sexual development. J. Anim. Sci. 60:1308-1317.

Cariolet, R., and R. Dantzer. 1984. Motor activity of pregnant tethered sows. Ann. Rech. Vet. 15:257-261.
Carlstead, K., J. L. Brown, S. L. Monfort, R. Killens, and D. Wildt. 1992. Urinary monitoring of adrenal responses to psychological stressors in domestic and nondomestic fields. Zoo Biol. 11:165-176.

Cryer, P. E. 1980. Physiology and pathophysiology of the human sympathoadrenal neuroendocrine system. N. Engl. J. Med. 303:436-444.

Dantzer, R., and P. Mormède. 1983. Stress in farm animals: A need for reevaluation. J. Anim. Sci. 57:6-18.

Del Rio, G., C. Carani, A. Baldini, P. Marrama, and L. Della Casa. 1990. Chronobiology of catecholamine excretion in normal and diabetic men. J. Endocrinol. Invest. 13:575-580.

Fibiger, W., G. Singer, A. J. Miller, S. Armstrong, and M. Datar. 1984. Cortisol and catecholamines changes as functions of timeof-day and self-reported mood. Neurosci. Biobehav. Rev. 8:523-530.

Gold, P. W., G. P. Chrousos, J. Licino, and M. L. Wong. 1996. Stress system abnormalities in melancholic and atypical depression: Molecular, pathophysiological, and therapeutic implications. Mol. Psychiatry 1:257-264.

Hay, M., and P. Mormède. 1997a. Determination of catecholamines and methoxy-catecholamines excretion patterns in pig and rat urine by ion-exchange liquid chromatography with electrochemical detection. J. Chromatogr. B. 703:15-23.

Hay, M., and P. Mormède. 1997b. Improved determination of urinary cortisol and cortisone or corticosterone and 11-dehydrocorticosterone by high-performance liquid chromatography with ultraviolet absorbance detection. J. Chromatogr. B. 702:33-39.

Janssens, C.J.J.G., F. A. Helmond, and V. M. Wiegant. 1995a. Chronic stress and pituitary-adrenocortical responses to corticotropinreleasing hormone and vasopressin in female pigs. Eur. J. Endocrinol. 132:479-486.

Janssens, C.J.J.G., F. A. Helmond, and V. M. Wiegant. 1995b. The effect of chronic stress on plasma cortisol concentrations in cyclic female pigs depends on the time of day. Domest. Anim. Endocrinol. 12:167-177.

Kattesh, H. G., G. A. Baumbach, B. E. Gillespie, J. F. Schneider, and J. T. Murai. 1997. Distribution between protein-bound and free forms of plasma cortisol in the gilt and fetal pig near term. Biol. Neonate 72:192-200.

Klemcke, H. G. 1995. Placental metabolism of cortisol at mid- and late gestation in swine. Biol. Reprod. 53:1293-1301.

Klemcke, H. G., and R. K. Christenson. 1997. Porcine fetal and maternal adrenocorticotropic hormone and corticosteroid concentrations during gestation and their relation to fetal size. Biol. Reprod. 57:99-106.

Klemcke, H. G., J. A. Nienaber, and G. L. Hahn. 1989. Plasma adrenocorticotropic hormone and cortisol in pigs: Effects of time of day on basal and stressor-altered concentrations. Proc. Soc. Exp. Biol. Med. 190:42-52.

Lindholm, J. 1973. The renal excretion of cortisol. J. Clin. Lab. Invest. 31:115-118.

Linsell, C. R., S. L. Lightman, P. E. Mullen, M. J. Brown, and R. C. Causon. 1985. Circadian rhythms of epinephrine and norepinephrine in man. J. Clin. Endocrinol. Metab. 60:1210-1215.

Maes, M., C. Vandervorst, E. Suy, B. Minner, and J. Raus. 1991. A multivariate study of simultaneous escape from suppression by dexamethasone of urinary free cortisol, plasma cortisol, adrenocorticotropic hormone and $\beta$-endorphin in melancholic patients. Acta Psychiatr. Scand. 83:480-491.

Meulenberg, P.M.M., and J. A. Hofman. 1990. Differences between concentrations of salivary cortisol and cortisone and of free cortisol and cortisone in plasma during pregnancy and postpartum. Clin. Chem. 36:70-75.

Meunier-Salaün, M.-C., F. Gort, A. Prunier, and W.G.P. Schouten. 1991. Behavioural patterns and progesterone, cortisol and prolactin levels around parturition in European (Large White) and Chinese (Meishan) sows. Appl. Anim. Behav. Sci. 31:43-59.

Meunier-Salaün, M. C., M. N. Vantrimponte, A. Raab, and R. Dantzer. 1987. Effect of floor area restriction upon performance, behavior 
and physiology of growing-finishing pigs. J. Anim. Sci. 64:1371-1377.

Morineau, G., A. Boudi, A. Barka, M. Gourmelen, F. Degeilh, N. Hardy, A. Al-Halnak, H. Soliman, J. P. Gosling, R. Julien, J. L. Brerault, P. Boudou, J. M. Villette, A. Pruna, H. Galons, and J. Fiet. 1997. Radioimmunoassay of cortisone in serum, urine, and saliva to assess the status of the cortisol-cortisone shuttle. Clin. Chem. 43:1397-1407.

Mormède, P., S. Garcia-Belenguer, J. Dulluc, and C. Oliver. 1994. Independent segregation of a hyperactive hypothalamic-hypophyso-adrenal axis and a reduced behavioural reactivity in pigs. Psychoneuroendocrinology 19:305-311.

Mullen, P. E., S. Lightman, C. Linsell, P. McKeon, P. S. Sever, and K. Todd. 1981. Rhythms of plasma noradrenaline in man. Psychoneuroendocrinology. 6:213-222.

Pollmann, D. S., D. M. Danielson, and E. R. Peo, Jr. 1979. Value of high fiber diets for gravid swine. J. Anim. Sci. 48:1385-1393.

Ramonet, Y., M. C. Meunier-Salaün, and J. Y. Dourmad. 1999. Highfiber diets in pregnant sows: Digestive utilization and effects on the behavior of the animals. J. Anim. Sci. 77:591-599.
Rosner, W. 1990. The functions of corticosteroid-binding globulin and sex hormones-binding globulin: Recent advances. Endocr. Rev. 11:80-91.

Scöfl, C., C. Becker, K. Prank, A. Von zur Mühlen, and G. Brabant. 1997. Twenty-four-hour rhythms of plasma catecholamines and their relation to cardiovascular parameters in healthy young men. Eur. J. Endocrinol. 137:675-683.

Smith, R., and M. Thomson. 1991. Neuroendocrinology of the hypothalamo-pituitary-adrenal axis in pregnancy and the puerperium. Baillieres Clin. Endocrinol. Met. 5:167-186.

Stewart, P. M., and C.R.W. Edwards. 1990. Specificity of the mineralocorticoid receptor. Crucial role for the $11 b$-hydroxysteroid dehydrogenase. Trends Endocrinol. Metab. 1:225-230.

Tomitaka, S. I., K. Sakamoto, A. Tamura, I. Kojima, and H. Fujita. 1996. Dexamethasone suppression test by measuring spot urinary free cortisol in depression. Biol. Psychiatry 39:220-222.

Young, J. B., R. M. Rosa, and L. Landsberg. 1984. Dissociation of sympathetic nervous system and adrenal medullary responses. Am. J. Physiol. 247:E35-E40. 